\title{
Article \\ Applications of Electromagnetic Induction and Electrical Resistivity Tomography for Digital Monitoring and Assessment of the Soil: A Case Study of Al-Ahsa Oasis, Saudi Arabia
}

\author{
Maged Mohammed ${ }^{1,2, *(\mathbb{C}}$, Ahmed El Mahmoudi ${ }^{3}{ }^{(-)}$and Yousef Almolhem ${ }^{4}$ \\ 1 Date Palm Research Center of Excellence, King Faisal University, Al Hofuf 31982, Saudi Arabia \\ 2 Agricultural and Biosystems Engineering Department, Faculty of Agriculture, Menoufia University, \\ Shebin El Koum 32514, Egypt \\ 3 Geology Department, Faculty of Science, Mansoura University, Mansoura 35516, Egypt; \\ mahmoudi@mans.edu.eg \\ 4 Department of Environment and Agricultural Natural Resources, College of Agricultural and Food Sciences, \\ King Faisal University, Al Hofuf 31982, Saudi Arabia; yalmolhem@kfu.edu.sa \\ * Correspondence: memohammed@kfu.edu.sa
}

Citation: Mohammed, M.;

El Mahmoudi, A.; Almolhem, Y.

Applications of Electromagnetic

Induction and Electrical Resistivity

Tomography for Digital Monitoring and Assessment of the Soil: A Case Study of Al-Ahsa Oasis, Saudi

Arabia. Appl. Sci. 2022, 12, 2067.

https://doi.org/10.3390/

app12042067

Academic Editors: Filippos

Vallianatos and Vassilis Sakkas

Received: 10 January 2022

Accepted: 13 February 2022

Published: 16 February 2022

Publisher's Note: MDPI stays neutral with regard to jurisdictional claims in published maps and institutional affiliations.

Copyright: (C) 2022 by the authors. Licensee MDPI, Basel, Switzerland. This article is an open access article distributed under the terms and conditions of the Creative Commons Attribution (CC BY) license (https:// creativecommons.org/licenses/by/ $4.0 /)$.

\begin{abstract}
Al-Ahsa Oasis is one of the main and oldest agricultural centers in Saudi Arabia and one of the largest natural oases in the world. It is the largest irrigated agricultural oasis worldwide. The cultivated area is about 12,000 hectares in the region of Al-Ahsa. Groundwater was considered the main water source, if not the only source, for the different purposes of Al-Ahsa Oasis. However, due to groundwater depletion from these aquifers, treated wastewater is currently used to meet the shortage of irrigation water at Al-Ahsa Oasis. Today, several problems affect the agricultural productivity at Al-Ahsa Oasis, and modern geophysical techniques could contribute effectively to solving these problems; such problems are increasing soil salinity and the existence of a hardpan layer in some parts of the Al-Ahsa oasis. The soil texture is considered a critical factor to be taken into consideration. Therefore, the objectives of this study were to evaluate the effectiveness of modern geophysical techniques to study the agricultural aspects of Al-Ahsa oasis. Ten profiles of 2-D electrical tomography using SuperSting R8/IP 8 channel multielectrode resistivity and IP imaging system with 112 electrodes at one-meter spacing were implemented. Moreover, twenty electrical conductivity profiles were measured of 2240 points using EM38-MK2 at vertical mode with transmitter-receiver coils of 0.5 and one meter spacing. The results indicated that the salinity variation along the measured profiles was changed vertically and laterally due to the changes in the soil type, texture, moisture content, sabkha, and the whole oasis. Analysis and interpretation of the interpreted resistively tomograms of the ten 2-D profiles indicate remarkably the different geoelectric units of different hydrogeological conditions and soil texture across the oasis. These results will be of good utility for farmers, development sectors, and research institutions, especially in agriculture development studies, at Al-Ahsa Oasis, to ensure the sustainability of agriculture in this important historical Oasis.
\end{abstract}

Keywords: agricultural geophysics; soil salinity; hardpan; soil texture; electrical resistivity tomography; electromagnetic induction; precision agriculture

\section{Introduction}

The methods of surface geophysics offer prompt and inexpensive means for subsurface characterization [1-3]. In addition, the surface geophysics technics provide information on subsurface properties, such as the layer's thickness and saturation zones, depth to bedrock, fracture zones, location and orientation of bedrock fractures, and faults. New developments in recent years are the use of 2-D electrical imaging/tomography surveys for mapping areas with moderately complex geology [4].

Agricultural geophysics is a modern discipline that applies noninvasive geophysical methods to obtain valuable soil surface and near-surface information. Geophysical 
techniques are becoming an important practical tool for many agricultural applications. Agricultural geophysical analyses are focused on delineating features over large areas within the soil profile (0 to $2 \mathrm{~m}$ depth) [5]. The most common geophysical methods predominantly used for agricultural purposes are direct current (DC) resistivity and electromagnetic induction. With the recent advent of precision agriculture, the ability to generate a large amount of information rapidly is becoming more critical than ever $[5,6]$. Site infrastructure assessment, hydrologic monitoring, and environmental investigations are just a few current and potential uses of near-surface geophysical methods in agriculture applications. In addition, modern geophysical techniques are being incorporated within site-specific agriculture to detect soil horizons, soil compaction, soil salinity, mapping of hardpan layer, and soil texture [6]. Today, with the advent of precision agriculture which employs data from multiple sources to enhance crop yields and assess soil quality to improve the costeffectiveness of crop management strategies, it is necessary to advance the agricultural geophysics methods for clay-pan depth determination, soil hydrologic characterization, soil nutrient monitoring, crop/tree root biomass surveying, identification of subsurface flow pathways, subsurface irrigation, drainage systems infrastructure detection, and soil compaction evaluation [7-9].

Electromagnetic (EM) instruments have been used extensively to determine the spatial distribution of soil attributes, including clay content [10,11], moisture [12], and soil salinity [13-16]. In addition, different studies have used EM instruments to determine the depth of a clay layer [17], soil types, and organic carbon fraction [18]. Al-Ahsa Oasis is located $70 \mathrm{~km}$ to the west of the Arabian Gulf, and it is also one of the main agricultural areas in Saudi Arabia (Figure 1).

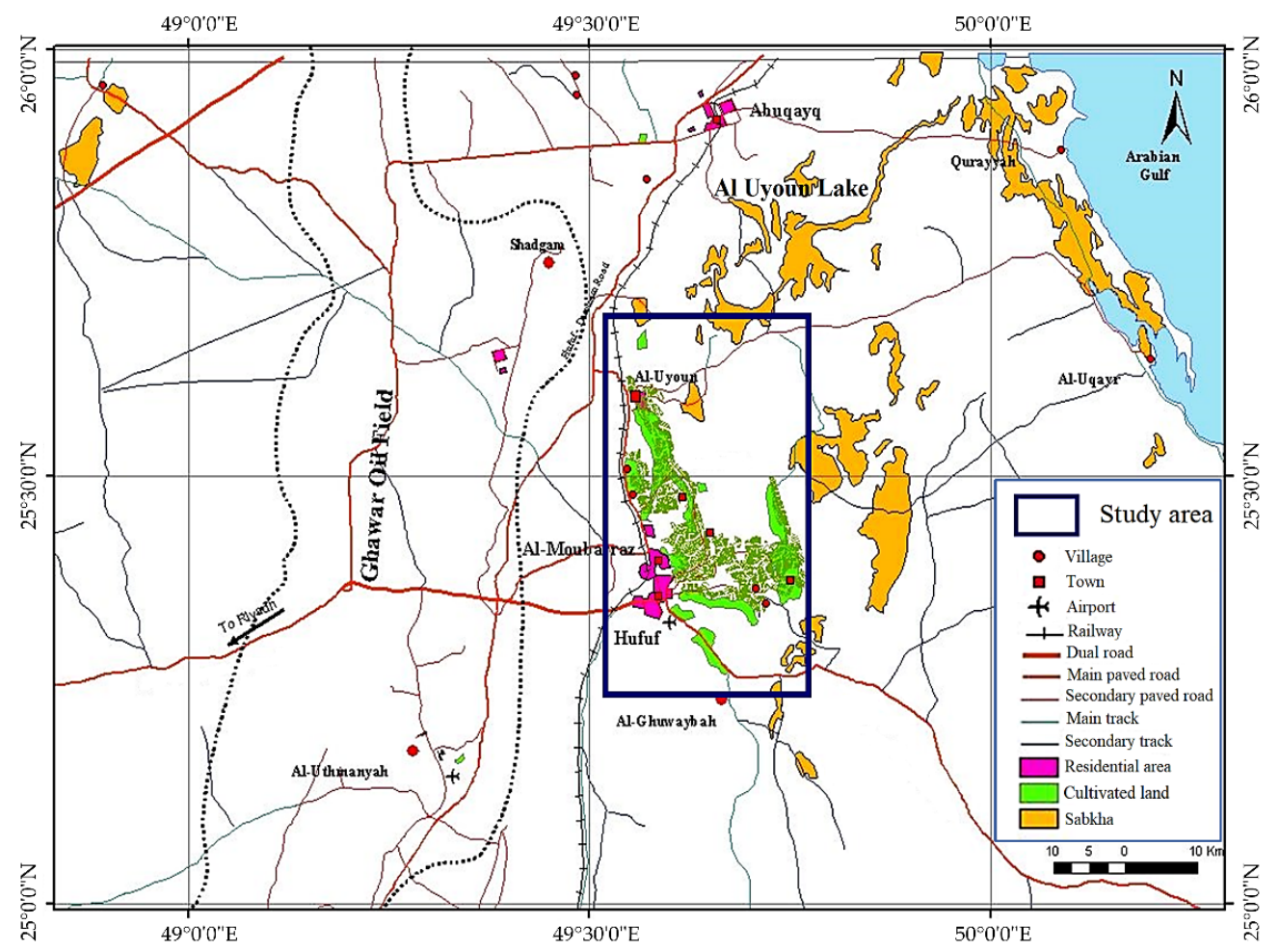

Figure 1. Location map of Al-Ahsa Oasis, Eastern Province, Saudi Arabia.

The cultivated area in the Al-Ahsa oasis is about 12,000 hectares. Groundwater was considered the main water source, if not the only source, for the different purposes of Al-Ahsa Oasis. As a consequence of the overexploitation of groundwater resources, a decline in groundwater levels is observed. The famous springs in the Al-Ahsa oasis are 
running dry. Furthermore, deterioration of groundwater quality is occurring, caused by upconing of deeper saline groundwater [19].

Due to groundwater depletion, treated wastewater is currently used to meet the shortage of irrigation water at Al-Ahsa Oasis. As a result, most groundwater is discharging from the Neogene aquifer. Today, due to excess overpumping, water depletion, and water deterioration, the signs of soil salinity at Al-Ahsa have become dominant [20,21].

Water and soil are the most critical factors that determine the success of agricultural activity in any location based on their characteristics. Some excavations at Al-Ahsa oasis indicated hardpan layers at different soil depths. Generally, hardpan is a term for a dense layer of soil below the uppermost topsoil layer. The negative impacts of the hardpan layer are that it is mainly impervious to water, restricts root growth, and makes it difficult for air, water, other gases, and organisms to move through the soil. Therefore, determining the existence of the hardpan layer nature and depth of its presence is very important in crop selection [22].

Al-Ahsa soils are underlain by an impermeable marl layer (mixtures of clay and calcium carbonate) at zero to $2 \mathrm{~m}$ depth below the ground surface. Excess irrigation water accumulates on top of this layer, forming a shallow water table beneath the soils of the Al-Ahsa Oasis. The water table depth is affected by varying depths to the marl layer, the soil texture, and depth and spacing between field drainage canals [23]. The irrigated arid zone of Al-Ahsa oasis faces twin problems of water scarcity and waterlogging accompanied by salinity. For more details about the studies related to the soil of Al Hassa, refer to [24-26]. Al-Dakheel [27] investigated the extent of soil salinity, irrigation water quality, and the relationship with the growth of vegetation, employing NDVI derived from Landsat satellite imagery. Al-Barrak and Al-Badawi [28] reported that salt-affected soils in Al-Ahsa region represent as much as $20 \%$ of the total area.

El Najem [21] studied the degraded agricultural soils at Al-Ahsa Oasis and reported that the decline in the soil productivity distinguished the soil degradation at Al-Ahsa oasis. He attributed that to human activities and the marginal climatic conditions, which are considered the most important sources of soil degradation. The soil chemical properties exhibited slightly alkaline $\mathrm{pH}$ values, extending between 7.33 and 7.86, while the soil salinity data, as EC (electrical conductivity) values, varied across the Al-Ahsa Oasis. He found several values that exceeded $400 \mathrm{mS} / \mathrm{m}$ (i.e., the minimum value of saline soils), reaching $7.80 \mathrm{dS} \mathrm{m}^{-1}$, implying the persistence of soil salinity conditions (i.e., saline soil) in the Oasis's agricultural soils. It was also noticed that the soil EC values increased with increasing soil depths, signifying the inefficient drainage systems and, hence, salinization of the soil profile in the Oasis [21].

Inland Sabkhas in Al-Ahsa area are salt-affected intermediate to dark brown soils found in relatively low relief areas. Sabkha in Al Hassa exists in very low relief areas, which are saturated with water (where groundwater rose and pushed salt to the surface).and may even have surface water [27].

Al-Ahsa drainage water is collected by earthen lateral open canals having depths of about $1 \mathrm{~m}$. The collected drainage water in the eastern part of Al-Ahsa oasis flows from the lateral's canals to three sub-main drainage canals, which are connected to the main drainage canal D2 as shown in Figure 2. The collected drainage water in this drainage flows towards an evaporation lake in Al Asfar $13 \mathrm{~km}$ to the east of the Oasis, while the drainage water in the northern sector flows from the lateral to the sub-main drainage canals that were connected to the main drainage canal D1. The drainage water in D1 flows towards an evaporation lake in Al Uyoun (see Figure 2). The collected water in both lakes remains in the winter season to be a source for cattle to drink, as well for shallow aquifer recharge. From December until April, the agricultural drainage water overflows from Al Uyoun lake through small waterways into the Arabian Gulf [23]. 


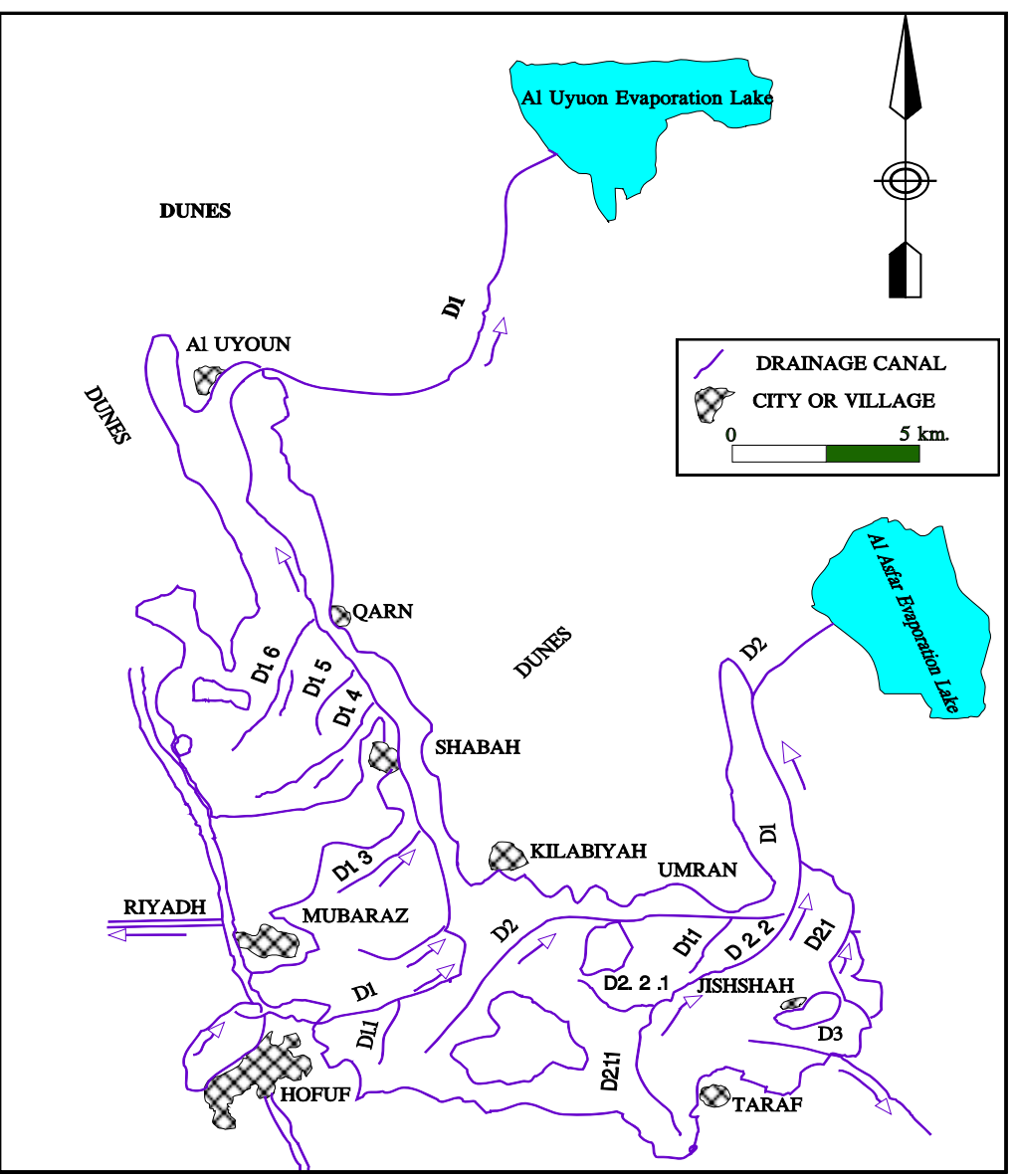

Figure 2. The main drainage system of Al-Ahsa [23].

For more details about the hydrogeology and the hydrochemical characterization of the groundwater of the Al-Ahsa area, refer to [19,27,29-32].

Soil surveys require quick and, when possible, nondisturbing estimations of numerous soil properties, such as salinity, texture, stone content, groundwater depth, and horizon sequence in soil profiles; however, conducting soil measurements with a high sampling density is costly and time-consuming. Conventional methods of soil analysis mostly require disturbing soil, removing soil samples, and analyzing them in a laboratory. So, the traditional methods used to acquire soil information involve intensive field surveys and laboratory analyses. As a consequence, only limited amounts of data are collected. In addition, the low resolution of the spatial data used to provide indicators of the distribution of water/soil properties and soil conditions may lead to interpretation errors and possibly errors in soil management. On the contrary, geophysical methods allow rapid measurement of soil electrical properties, such as electrical conductivity, resistivity, and potential, directly from the soil surface to any depth without soil disturbance. Modern geophysical techniques are a very efficient and effective tool for the nonintrusive gathering of continuous agricultural field data on many soil types, soil conditions, soil salinity, and underground topographies.

The objectives of this study were to evaluate the effectiveness of modern geophysical techniques to study the agricultural aspects of $\mathrm{Al}$ Hassa oasis.

\section{Materials and Methods}

\subsection{The Geophysical Investigations}

Electrical resistivity tomography (ERT) and Electromagnetic (EM) induction were implemented to achieve the objectives of this study. The DC resistively method of geophysical exploration is popular, has proved to be successful, and has many implications in 
agriculture, environmental studies, and hydrogeology. Moreover, the conductivity meter is an inexpensive, rapid, and effective means for mapping soil salinity. In this study, 2-D electrical resistivity measurements were carried out using a SuperSting R8/IP 8 channel multielectrode resistivity (Advanced Geosciences (AGI), Inc. Geoscience Dr., Austin Texas, TX, USA) and IP imaging system with 112 electrodes manufactured by Advanced Geosciences, Inc., (AGI), (Figure 3A), while the EM38-MK2 m (Geonics Limited, Meyerside Dr., Mississauga, Ontario, Canada) was used in vertical mode (Figure 3B) to measure the electrical conductivity (EC) along the study area.

(A)

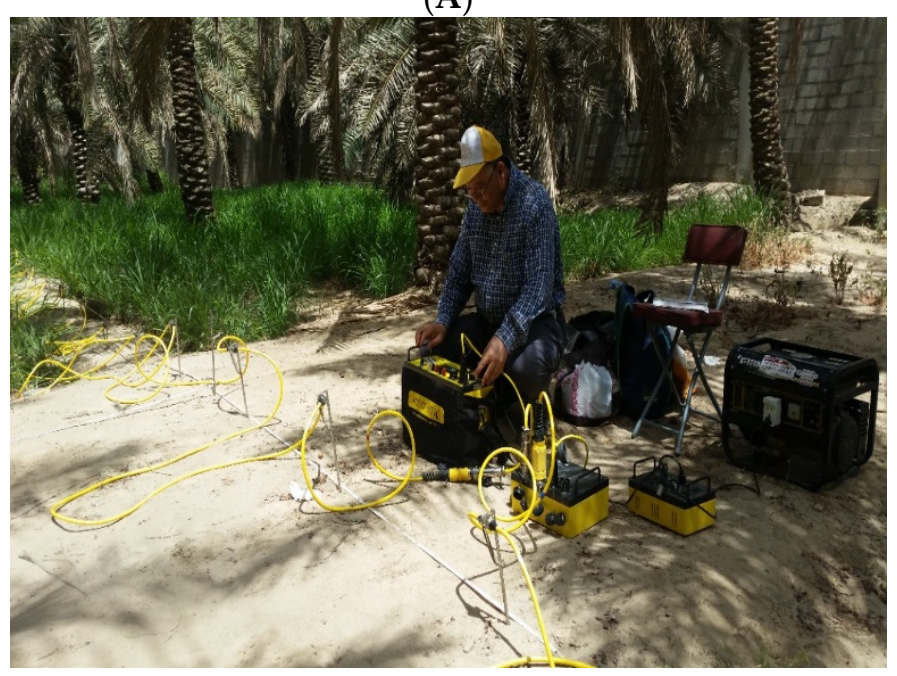

(B)

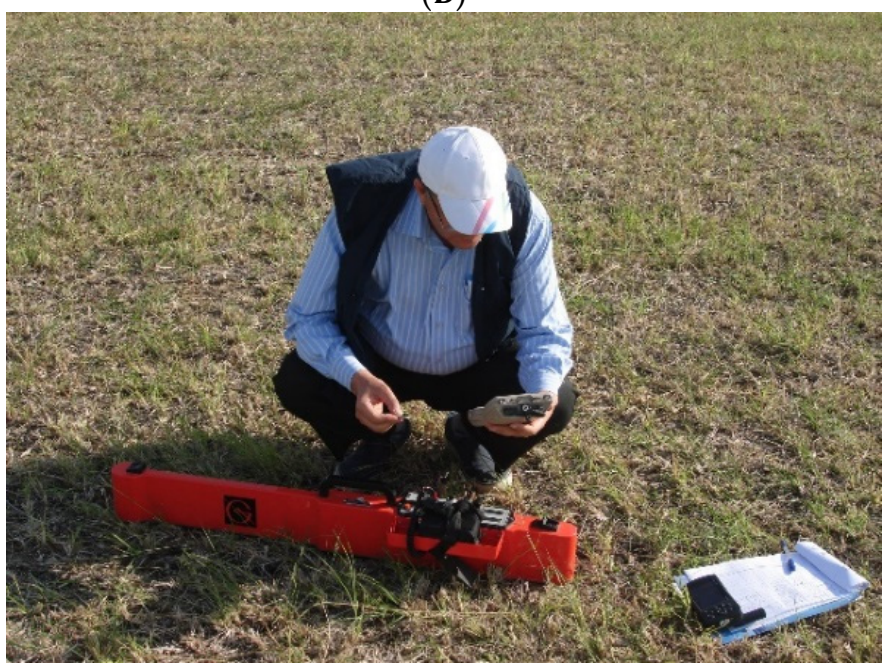

Figure 3. Geophysical data acquisition using the SuperSting R8/IP 8 resistivity (A) and the EM38MK2system electrical conductivities (B) at the study area.

Ten profiles of 2-D (P-1 to P-10) electrical tomography using the SuperSting R8/IP 8 multielectrode channel resistivity and IP imaging system with 112 electrodes at one-meter electrode spacing were implemented. The locations of these profiles were chosen to cover different zones across the entire Al Hassa oasis. Moreover, 2240 measuring points using EM38-MK2 at vertical mode with the transmitter-receiver of 0.5 and one-meter spacing were measured with twenty electrical conductivity profiles. Figure 4 shows the base map of the ten conducted 2-D profiles along the study area. It is worth mentioning that the EM38-MK2 measured electrical conductivity was measured at the 10 exact locations of the measured 2-D profiles to correlate soil conductivity / resistivity at near-surface (These lines are Labeled Line One-1, Line Two-1, etc.).

In contrast, the other ten EM38-MK2 electrical conductivities, each of them, were measured five meters away from the location of the 2-D transects. These EC lines are labeled Line One-2, Line Two-2, etc., to distinguish them on the data logger files from those measured at the exact locations of the 2-D transects. These ten EC lines (labeled Line One-2, Line Two-2, etc.) were measured for correlation with those measured at locations of the 2-D transects.

For more details about the irrigation water quality refer to, for example, Hussein et al. [31]. For the soils of Al Hassa, refer to El Najem [21]. 


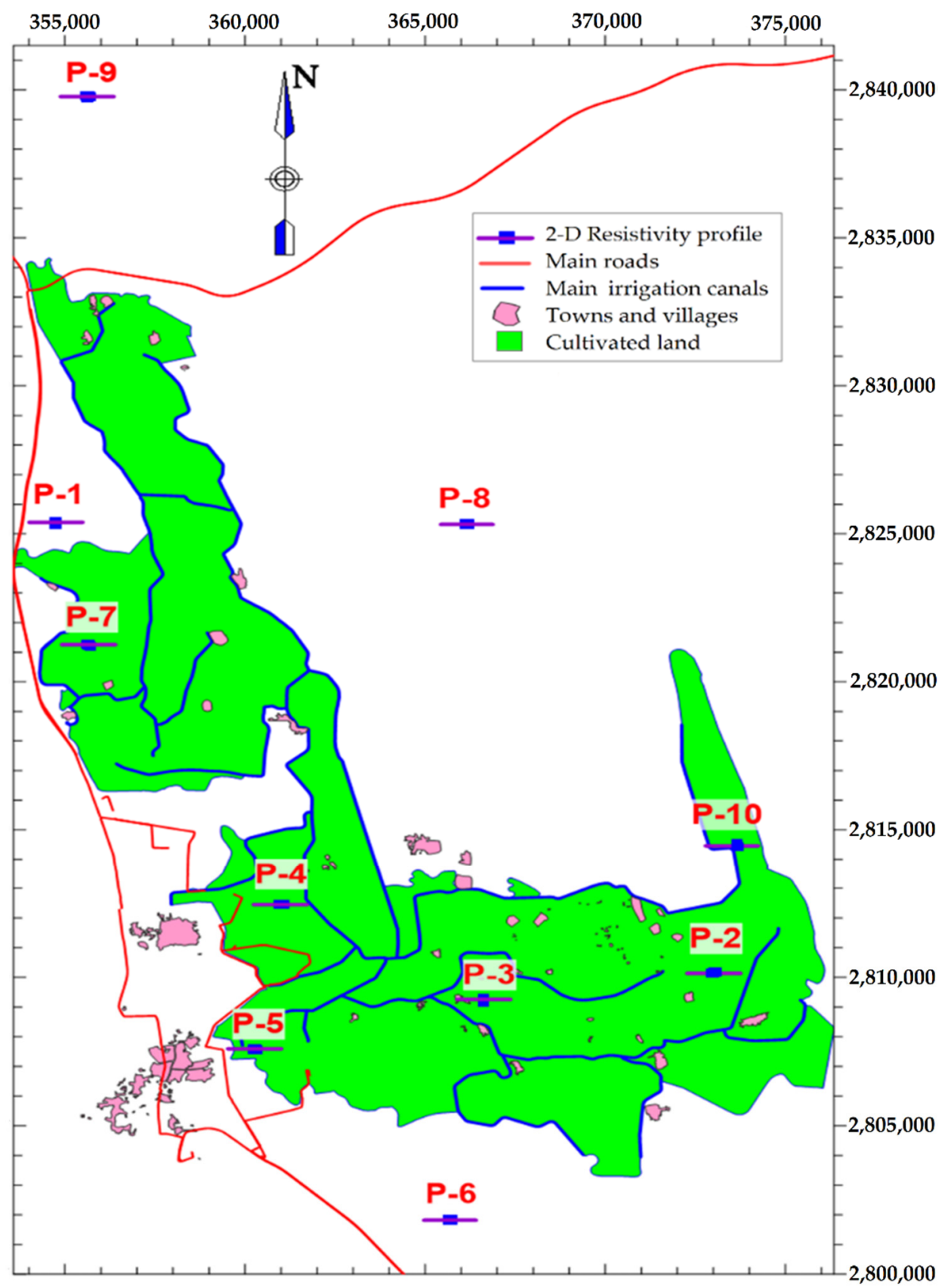

Figure 4. Base map showing the locations of the 2-D resistivity tomography profiles and EM38-MK2 at the study area.

\subsection{Two-Dimensional Resistivity Description and Data Acquisition}

The SuperSting R8/IP multielectrode resistivity provides apparent resistivity, induced polarization, and battery voltage. The measurement range is $\pm 10 \mathrm{~V}$, and the max measuring resolution is $30 \mathrm{nV}$, depending on the voltage level. The internal transmitter is $200 \mathrm{~W}$ and the external $15 \mathrm{~kW}$. The output current ranges from 1 to $2000 \mathrm{~mA}$ continuous, and it can be measured with high accuracy. The output voltage is $800 \mathrm{~V}$, and the actual electrode voltage depends on the ground resistivity and transmitted current. There are eight input channels.

The input gain ranges automatically and always uses the receiver's full dynamic range. The input impedance is more than $50 \mathrm{M} \Omega$. The system calibration is conducted digitally by the microprocessor, based on the correction values stored in the memory. The supported configurations in manual mode are resistance, Wenner, Schlumberger, pole-dipole, dipoledipole, and pole-pole, and any configuration can be programmed in automatic mode. 
The operating system is stored in a reprogrammable memory. For each measurement, full-resolution readings of the mean value and error are stored along with the user-entered coordinates and time of the day.

The displayed and stored data in the memory are apparent resistivity (Ohm-m), current intensity $(\mathrm{mA})$, and measured voltage $(\mathrm{mV})$ for each measurement. In addition, the data can also be realtime displayed on an Android device with bright color, transmitter/receiver plot, IP curves, and contact resistance measurements. The internal SuperSting memory in the resistivity mode can store more than 79,000 measurements and can store more than 26,000 measurements in the combined resistivity/induced polarization mode. The RS-232C channel is available to dump the data from the instrument to a Windows-type computer based on the user command. The operating time of the SuperSting R8/IP depends on survey conditions and the used battery size. The internal circuitry in the auto mode can adjust the current to save energy. The operating temperature ranges from -5 to $+50{ }^{\circ} \mathrm{C}$.

The resistivity method depends on the injection of the electrical current (I) into the ground by using two current electrodes A (source) and B (sink), and two potential electrodes $\mathrm{M}$ and $\mathrm{N}$, computing the resulting potential differences $(\Delta \mathrm{V})$ as illustrated in Figure 5 . Increasing the electrode spacing results in a deep depth of investigation, where the electric current passes through the investigated subsurface targets. By considering the subsurface structure, the depth of investigation represents about $20 \%$ to $40 \%$ of the spacing of the current electrodes [33].

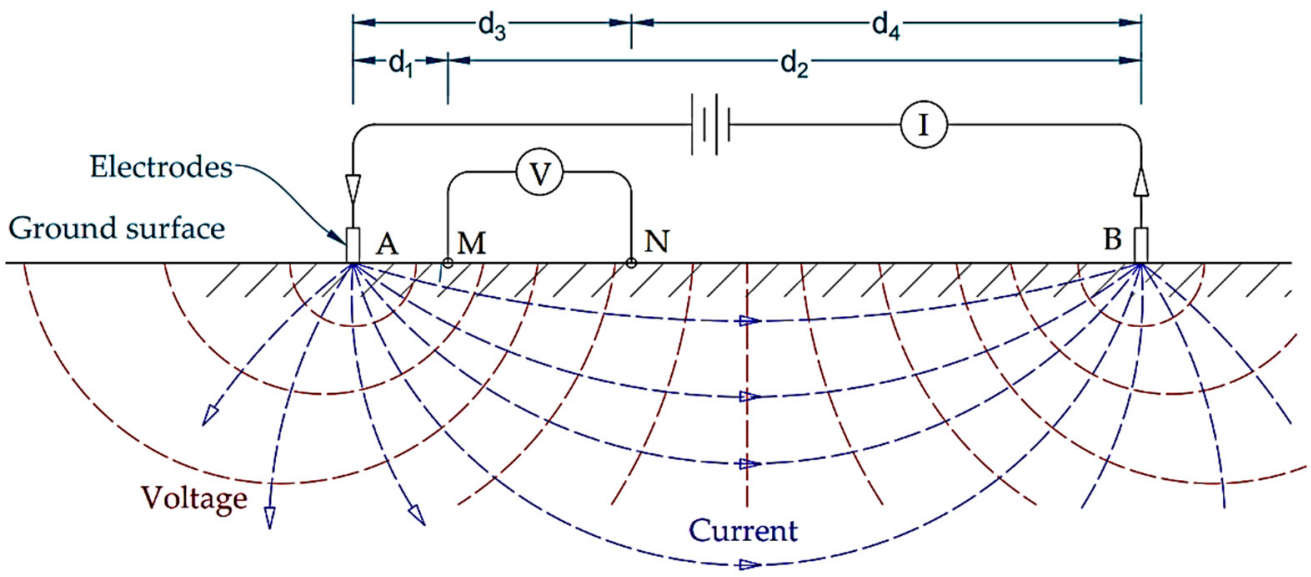

Figure 5. Schematic diagram illustrating the basic concept of electrical resistivity measurement.

The following Equations (1) and (2) give the apparent electrical resistivity of the subsurface

$$
\rho_{a}=\frac{V_{M N}}{I} G
$$

where $G$ is the Geometrical Factor and is given by

$$
G=\frac{2 \pi}{1 / d_{1}-1 / d_{2}-1 / d_{3}-1 / d_{4}}
$$

where $d_{1}, d_{2}, d_{3}$, and $d_{4}$ are the distances of the potential electrodes $\mathrm{M}$ and $\mathrm{N}$ from the current electrodes (A and B), see Figure 5.

For more details about resistivity and survey deployment basics, refer to Musset and Khan [34] and Reynolds [35]. In this study, the 2D electrical resistivity measurements were carried out using the SuperSting R8/IP 8 multielectrode channel resistivity and IP imaging system with 112 electrodes at one-meter spacing manufactured by AGI Advanced Geosciences, Inc., Austin, TX, USA (Figure 3A).

A combination of dipole-dipole, Wenner-Schlumberger, and pole-dipole configurations at each transect of the conducted ten 2-D resistivity profiles was implemented and merged during the processing of the interpretation of resistivity data for each transect. 
The coordinates of the conducted 2-D profiles were measured using the GPS system. The quality of the data acquisition was entirely controlled by the computer software, which, before starting any measurement, checked the electrode connectivity to the soil and the magnitude of the contact resistances. The $1 \mathrm{~m}$ electrode spacing was chosen with an estimated investigation depth about $20 \mathrm{~m}$ below the ground. The apparent resistivity data were inverted to create a model of the resistivities of the subsurface using AGI Earthimager 2-D Software (after Advanced Geosciences, Inc., Austin, TX, USA). With this software, the data collected with the AGI SuperSting earth imaging resistivity instruments can be interpreted into easy-to-read 2-D earth sections (resistivity tomograms). A more accurate subsurface model is the two-dimensional (2-D) model, where the resistivity changes in the vertical and horizontal directions along the survey line are recorded. 2-D resistivity profiling was carried out by making many measurements at different profile locations and offsets. Finally, the 2-D resistivity profiling data were inverted using AGI Earthimager 2-D Software (after Advanced Geosciences, Inc., Austin, TX, USA) to create a tomogram-like resistivity model along a subsurface section that detected different salinity water zones [4]. AGI EarthImager 2-D software (after AGI Inc., Austin, TX, USA) was used for resistivity data inversion. AGI EarthImager 2-D software is a two-dimensional inversion modeling software for affordable resistivity and induced polarization (IP) imaging. Using this software, any array or mixed data from Schlumberger, pole-pole, pole-dipole, dipole-dipole, or Wenner electrode arrays can be inverted.

\subsection{EM38-MK2 Description and Data Acquisition}

EM38-MK2 provides the measurements of in-phase (magnetic susceptibility) and quad-phase (conductivity) components within two different depth ranges without any requirement to contact with or penetration of the instrument into the soil. The maximum practical depth of exploration is $1.5 \mathrm{~m}$. Therefore, the EM38-MK2 applications in general soil and agriculture sciences are typical. The EM38-MK2 contains two receiver coils, divided to $1 \mathrm{~m}$ and $0.5 \mathrm{~m}$ from the transmitter, supplying the data from the effective depth ranges of $1.5 \mathrm{~m}$ and $0.75 \mathrm{~m}$, respectively when placed in the vertical dipole orientation. On the other hand, it supplies the data from the effective depth ranges of $0.75 \mathrm{~m}$ and $0.375 \mathrm{~m}$, respectively at horizontal dipole orientation. Once the EM38-MK2 is positioned within the collapsible calibration stand, the instrument can be calibrated automatically within seconds, without any necessity for iterative adjustments. In addition, the EM38-MK2 is supported by temperature equilibrium circuitry to improve temperature-related drift aspects. The data can be collected by any appropriate field computer or the DAS70-AR Data Acquisition System, which can be connected by either Bluetooth wireless technology or RS-232 serial cable. The DAS70-AR provides an improved level of support for data collection, and it includes a rugged field computer with 8 GB storage memory. For more details about this instrument, refer to Geonics Ltd., Mississauga, ON, Canada.

The diagram of the EM38 and its related electromagnetic fields is described in Figure 6. The primary magnetic field ( $\mathrm{Hp}$ ) is generated from the transmitting coil (Tx) at one end of the sensor, this field produces current loops in the ground below, and in turn, the current loops generate their own magnetic field (Hi). The generated secondary field is superimposed on the primary field, and both $\mathrm{Hp}$ and $\mathrm{Hi}$ are measured in a receiving coil $(\mathrm{Rx})$ at the other end of the sensor [36]. The meter is intended to be placed or held in either the horizontal or vertical orientation; this orientation position controls the signal penetration depth and depth weighting response pattern. In a homogeneous soil profile, the vertical (EMV) signal penetrates to a depth of 1.5-2 m, while the horizontal (EMH) signal primarily reflects the shallower soil zone (0.75-1.0 m); Manual of EM38-MK2, (Geonics Limited). 


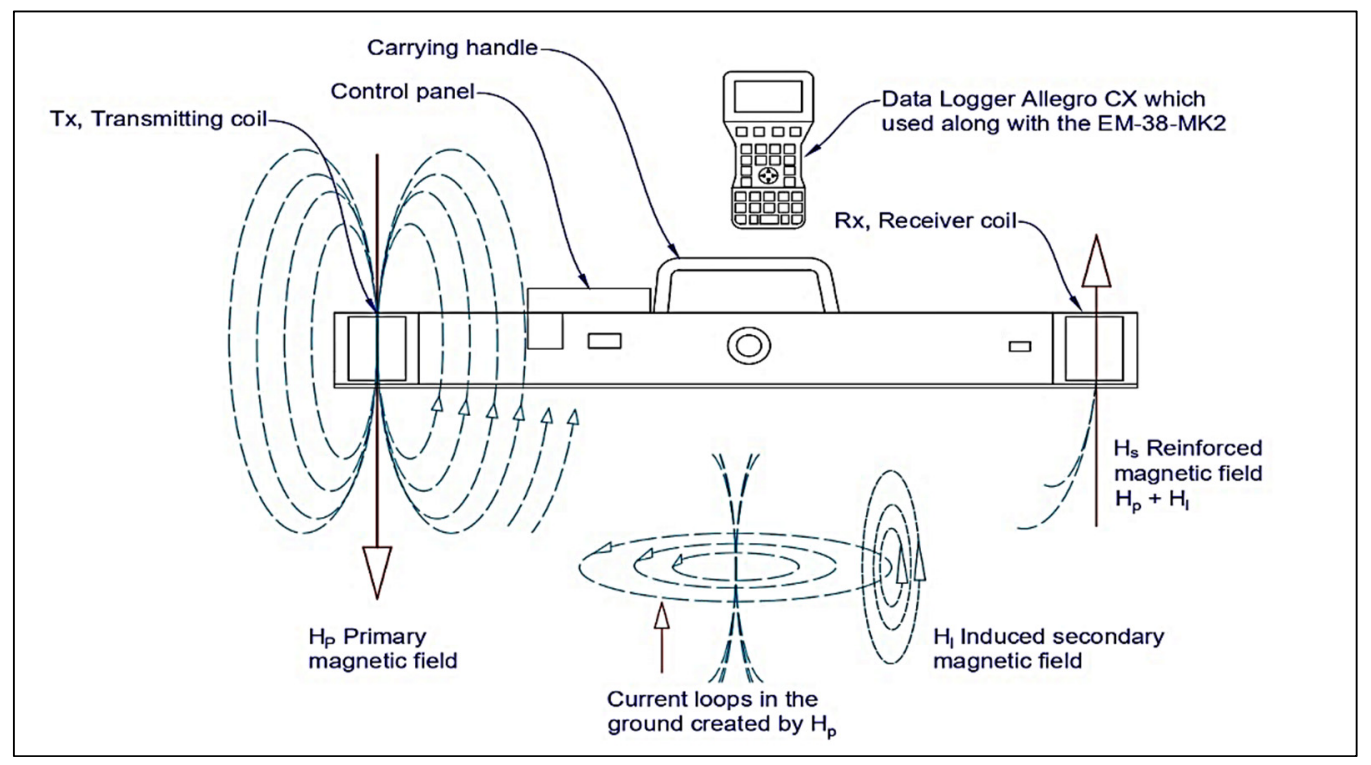

Figure 6. Diagram of an EM38 m showing the principles of operation.

Therefore, the instrument works by emitting an alternating current through a transmitter coil, which induces a primary magnetic field to pass perpendicular to the coil orientation and into the adjacent media. Eddy currents are generated as these currents pass through the coil. This strength is a function of the (a) amount of negative charge on the clay particle; (b) clay content; (c) concentrations of salts in the soil solution; and (d) soil moisture content. The more conductive the soil, the greater the secondary magnetic field produced. The ratio of the primary and secondary magnetic fields determines the apparent electrical conductivity (ECa).

Electromagnetic induction sensors, such as EM38-MK2, are becoming more widely used for mapping relative differences in soil characteristics in agricultural fields, including soil salinity; see [15]. In this study, EM38-MK2 was used in vertical mode to measure the electrical conductivity (EC) at 75 and $150 \mathrm{~cm}$ depths at about 2240 sites along the study area (see Figure 4). The acquired data using the EM38-MK2 conductivity meter were processed using the DAT38MK2 Ver. 1.05 package (Geonics Limited) and exported to XYZ format for the twenty EC measured profiles.

\section{Results and Discussion}

\subsection{Two-Dimensional Resistivity Tomography Data}

To tie the inverted 2-D resistivity tomograms with the available lithological and hydrogeological information, previous work conducted by different authors, for example $[16,20,22,24,25]$, have been correlated with 2-D inverted resistivity tomograms. Using an iterative smoothness-constrained least-squares inversion method [37,38], apparent resistivity data collected by the 2D-DC resistivity system were inverted using AGI Earthimager 2D Software (after Advanced Geosciences, Inc.) to create a subsurface resistivity model that approximates the actual subsurface resistivity distribution [38]. Figure 7 shows the inversion of profile P- 6 (see Figure 4 for location), where the resistivity field-data is presented on the upper part of the section, resistivity models are presented on the middle part of the section, and synthetic-data inversions are shown on the lower part of the section. 


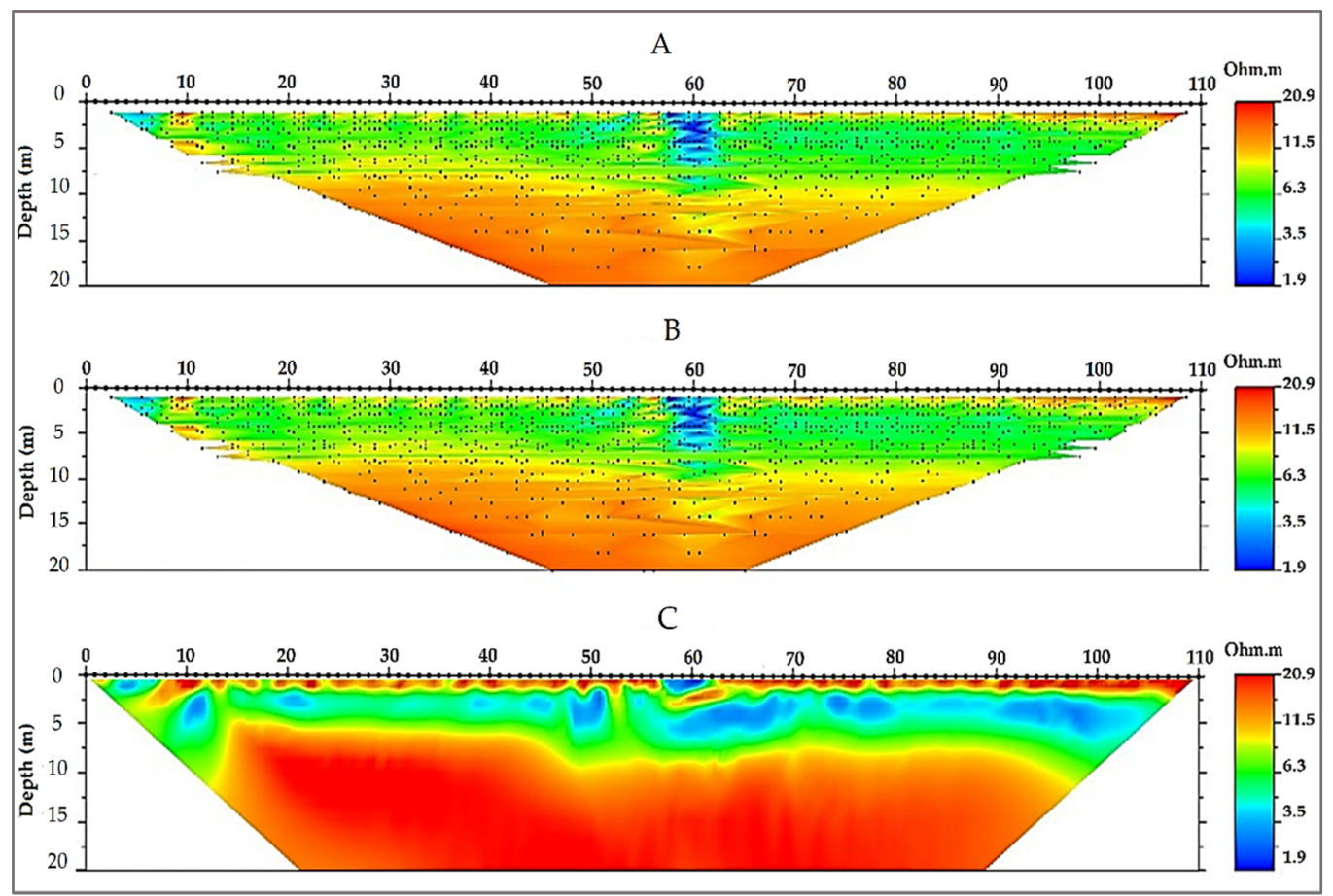

Figure 7. Two-dimensional resistivity section for the location P-6. The upper section is the measured resistivity (A), the middle section is the calculated resistivity $(\mathbf{B})$, and the lower section is the inverted resistivity (C) (see Figure 4 for location).

Investigations of the constructed 2-D resistivity tomograms along with the data from the previous work conducted by different authors at Al-Ahsa Oasis, as well some soil pits dug by local farmers, helped in the interpretation of the resistivity tomograms and in the mapping of the near-surface condition of the soil along the study area which has its impacts on soil characterization.

Figure 8 shows the combined tomograms with their locations across the Al-Ahsa Oasis; vertical and lateral variations of different lithological units are recognized. Referring to Figure 8 and investigations of these 2-D Tomograms of the location of both of Al Asfar and Al Uyoun lakes, it is found that the main three identified geoelectric-lithologic units along these tomograms are: 


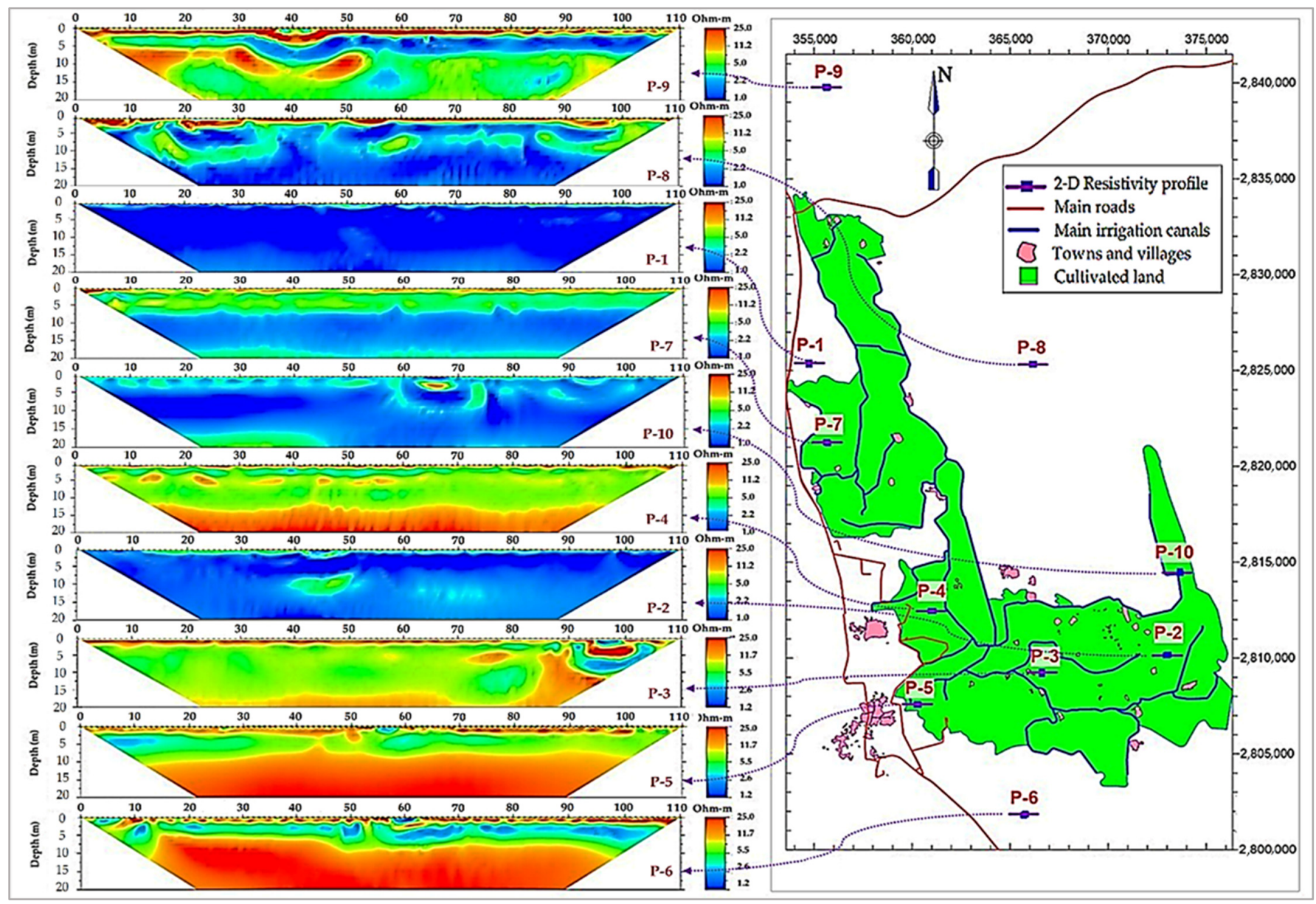

Figure 8. The Combined 2-D inverted tomograms show how the resistivity variations vertically and horizontally at the ten tested locations from 1 to 10 (P-1 to P-10), according to the positions, due to change in hydrogeological conditions and lithology and soil texture.

Layer-1 is a topsoil zone of loose to weakly consolidated sand. This zone corresponds to the upper part of the very resistive layer. The resistive nature of this layer is indicative of dry conditions in the upper part of the measured 2-D transects. However, and referring to Figure 8 , it is noticed that resistivity values of this layer have relatively high values (above $10 \mathrm{Ohm}-\mathrm{m}$ ) along 2-D transects of profiles 1, 10, and 7 (P-1 to P-10, see Figure 4 for locations); these are attributed to both dry conditions and the coarse grains sand at these locations. On the other hand, this layer at the 2-D transects of profiles 1, 10, and 2 (P-1, P-10, and P-2, Figure 8) have relatively low values due to the effect of Sabkha and clayey soil and the effects of the existence of both the Al Yuoun evaporation lake at the north of Al-Ahsa Oasis and of the Al Asfar Lake at the east of the Oasis. These match well with the results of Al-Dakheel et al. and El Mahmoudi et al. [27,39]. Referring to Figure 8, it is worth mentioning the alternating of high and low resistive parts at this layer (see, for example, P-9 at a distance of 30-50 m, Profile 10 at a distance of $60-75 \mathrm{~m}$, and Profile 3 at a distance of 90-105 $\mathrm{m}$. This indicates the inhomogeneity of this layer and variations of irrigation practices at the same farm (part of the farm is cultivated by vegetables and the other is date palm). Moreover, some farmers transport soils from other places to some locations at their farms.

Layer-2 has a moderate resistivity range of (2 to $10 \mathrm{Ohm}-\mathrm{m})$. This layer exists at different depth intervals (for example, 2-D transects of profiles P-4, P-5, P-6, P-8, and P-9, Figure 8). This layer is interpreted as a partially saturated layer, which makes its resistivity values less than of the topmost soil layer. 
Layer-3 is a thick zone below Layer-2. This layer has different resistivity ranges. The resistive nature of this third layer (above $10 \mathrm{Ohm}-\mathrm{m}$ ) is along 2-D transects of profiles 6, 5, 3 , and 4 (P-6, P-5, P-3, and P-4, Figure 8), which are located in the southwest of Al-Ahsa oasis. This layer at these locations is attributed to lithological changes and as well different hydrogeological conditions. The existence of Neogene limestone outcrops has been noticed at the surface and the near-surface in this part, while at the northern part, it does not exist. For more geological details of Al-Ahsa Oasis, refer to Hotzl et al. [40]. On the other hand, this layer has resistivities below 2 Ohm-m along with profiles 7, 1, 9, 8, 10, and 2 (P-7, P-1, P-9, P-8, P-10, and P-2, Figure 8) located in the north and east of Al-Ahsa oasis. However, and referring to Figure 8, it is noticed that this layer's resistivity values have relatively low values due to the effect of water saturation from both the Al Yuoun evaporation lake at the north of Al-Ahsa Oasis and of Al Asfar Lake at the east of the Oasis.

Figure 9 shows one of the dug pits beside 2-D profile 1 (P-1, Figure 8 ) and shows how the water table is very shallow and the saturation affects the resistivity values to be below 2 Ohm-m.

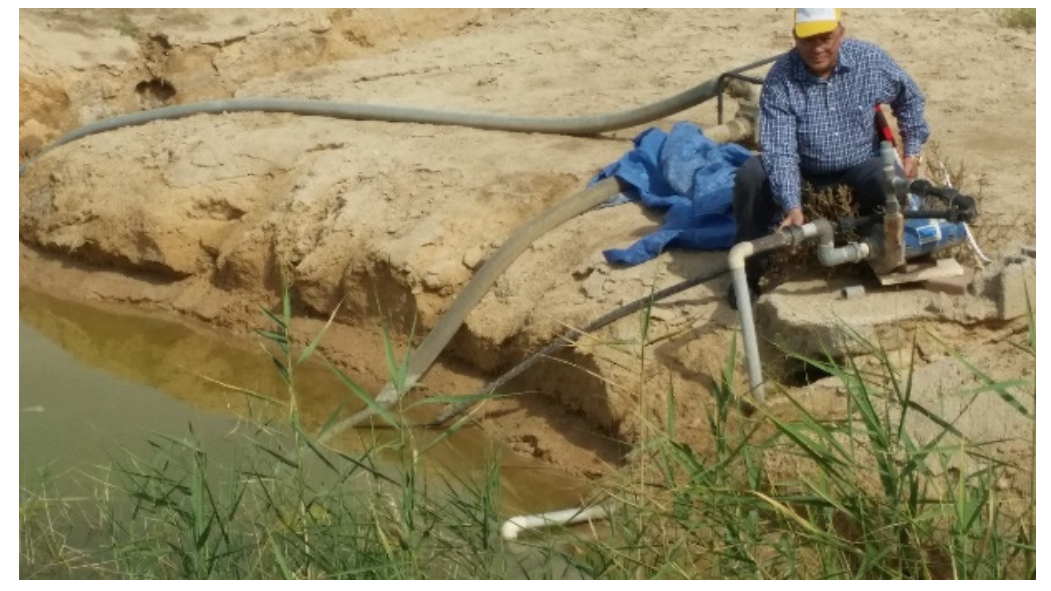

Figure 9. An image shows the dug pits and the shallow water table beside profile 1 (P-1, Figure 8 ).

A low resistivity layer was mapped along some 2-D transects, for example, profiles 6 , 9, and 8 (P-6, P-9, as well as P-8, Figure 8). This layer is a hardpan layer composed of marl, clay, mudstone, or shale [22]. The layer directly affects the level of soil water and thus the accumulation of salt in some locations resulting in the presence of some of the sites affected by the salt composed sabkha, especially if it is very shallow and this, in turn, increased the soil conductivity measured by EM38-MK2, as will be discussed below. Figure 10 shows some excavation and the existing hardpan layer at different depths near profile 6 (P-6, Figure 8).

\subsection{EM38-MK2 Results}

Twenty profiles using the EM38-MK2 in the vertical mode were conducted to measure the apparent electrical conductivity (ECa) at 75 and $150 \mathrm{~cm}$ depths, based on implemented coil separation ( 0.5 and $1 \mathrm{~m}$ separation in vertical mode). The data from about 2240 measuring points sites acquired by EM38-MK2 were automatically logged by a special Data Logger Allegro CX. It is worth mentioning that ten of the EM38-MK2 profiles of measured electrical conductivity had the same locations of the measured 2-D profiles, while the other ten electrical conductivities lines measured by EM38-MK2 were measured five meters away from the location of the 2-D and the EM38-Lines-Ones of electromagnetic. The exported electrical conductivity (ECa) values for each EM38 measuring line were averaged for the values measured at $1 \mathrm{~m}$ coil separation and those measured at 0.5 coil separation. For every ten lines, the electrical conductivity (salinity indicator) was plotted for both two different coil separations $(1 \mathrm{~m}$ and $0.5 \mathrm{~m})$. Figure 11 shows the combined averaged measuring lines using EM38-MK2 across the Al-Ahsa Oasis. Investigations of these lines show how the 
variation of conductivity changed with depth, according to the positions, due to changes in soil salinity conditions, lithology, and soil texture at each line. The following remarks can be noticed from Figure 11.

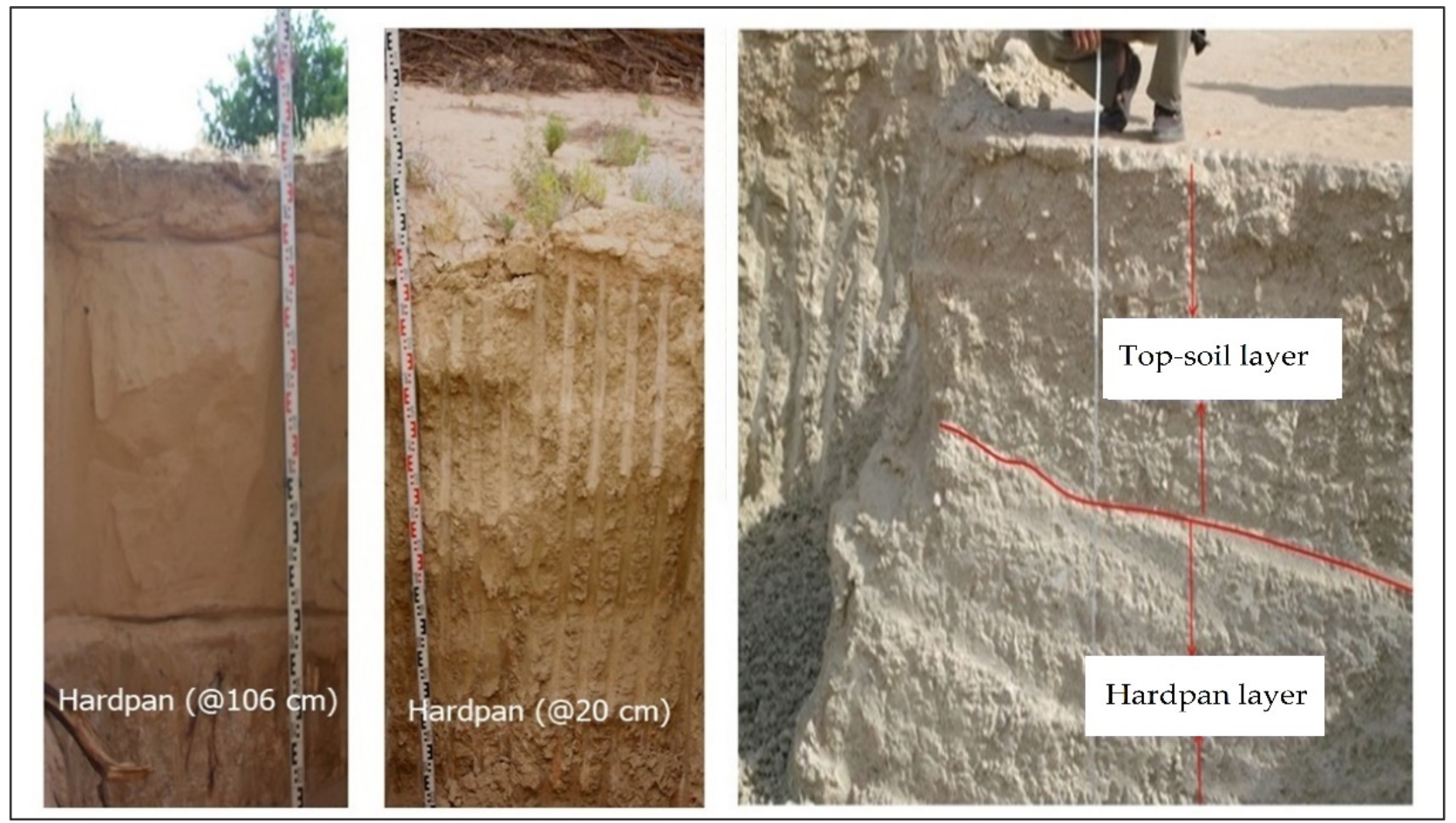

Figure 10. Some excavation and the existing hardpan layer at different depths near profile 6 (P-6, Figure 8).

The measured conductivity at lines located at the southwest of the study area was characterized by relatively low conductivities (maximum was $140 \mathrm{mS} / \mathrm{cm}$ ), see for example, Line 4 (Figure 12a) as compared with those lines measured at the north and east of the study area, see for example, line 7, Figure $12 \mathrm{~b}$ (maximum was $750 \mathrm{mS} / \mathrm{cm}$ ), which was about five times the maximum electrical conductivity at line 4 (P-4, Figure 12). These indicate the salinity of the soil at the north and east part of Al-Ahsa Oasis. The two evaporator lakes of $\mathrm{Al}$ Uyoun to the north and $\mathrm{Al}$ Afar to the east are the main reasons for the salinity increasing at these locations.

It is worth mentioning that there was a good match between the results of the 2D profiles and the EM38-MK2 profiles for the soil zones. For example, the topsoil of resistivity profile 5 (P-5) was resistive, see Figure 8 , which was confirmed by relatively low conductivities (maximum was about $150 \mathrm{mS} / \mathrm{cm}$ ). On the other hand, compared with those lines measured at the north of the study area, see resistivity profile 1 and the EM38-MK2 for this profile for the soil zones; they are characterized by high conductivity (low resistivity).

Generally, the measured conductivity at most lines indicated high values of conductivities at a coil separation of $1 \mathrm{~m}$ (greater depth); see for examples Lines 7, 8, and 10 of Figure $12 b, c$, and $d$, which are located at the north and east of the study area, while only two lines (line 4, Figure 12a) and line 3 (P-3, Figure 12) showed high values of conductivities at a coil separation of $0.5 \mathrm{~m}$ (shallow depth) compared with those at a $1 \mathrm{~m}$ coil separation, located in the southwest of the study area. 


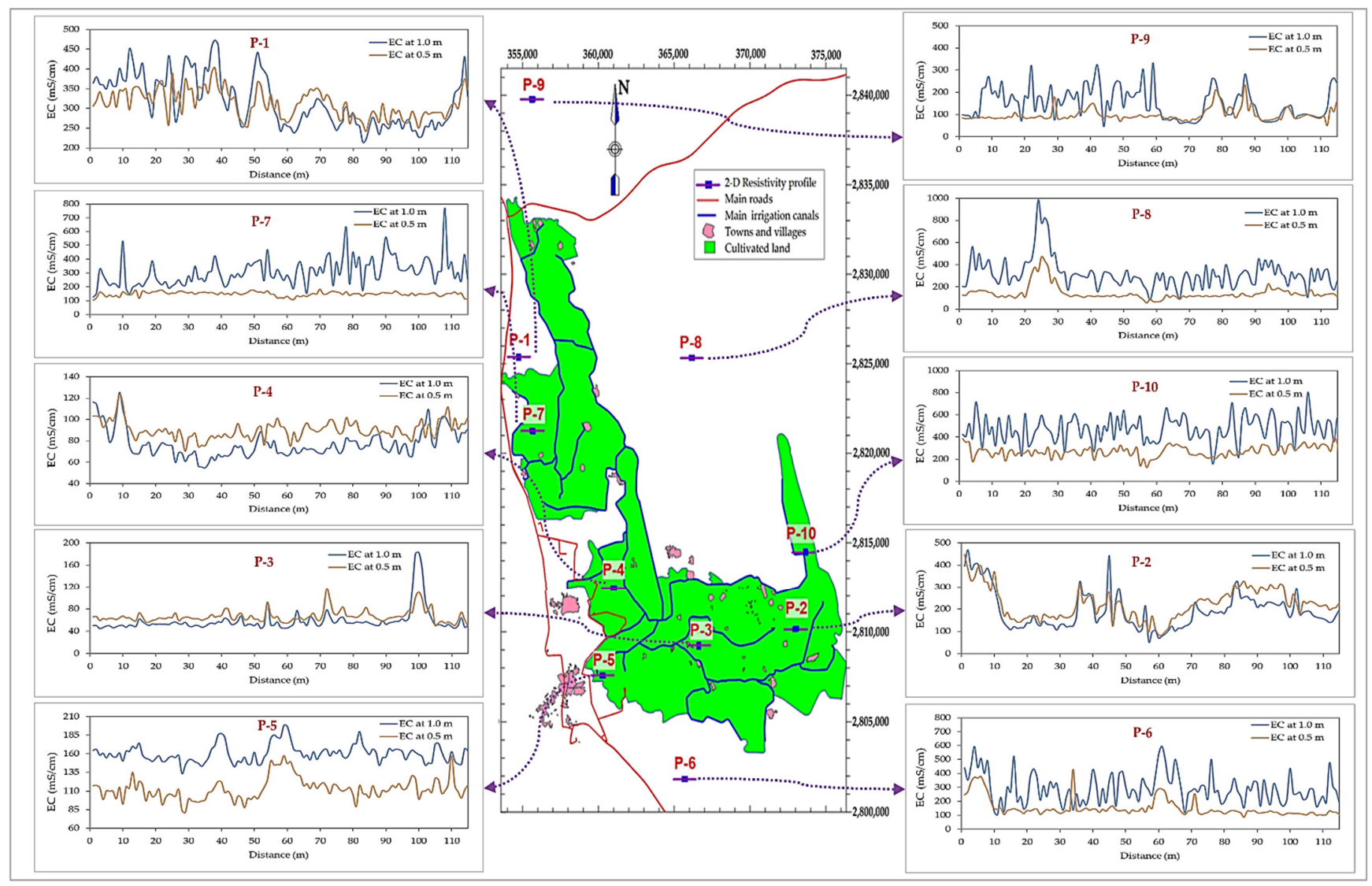

Figure 11. The combined averaged measuring lines at the ten tested locations from 1 to 10 (P-1 to P-10) using EM38-MK2 across the Al-Ahsa Oasis.
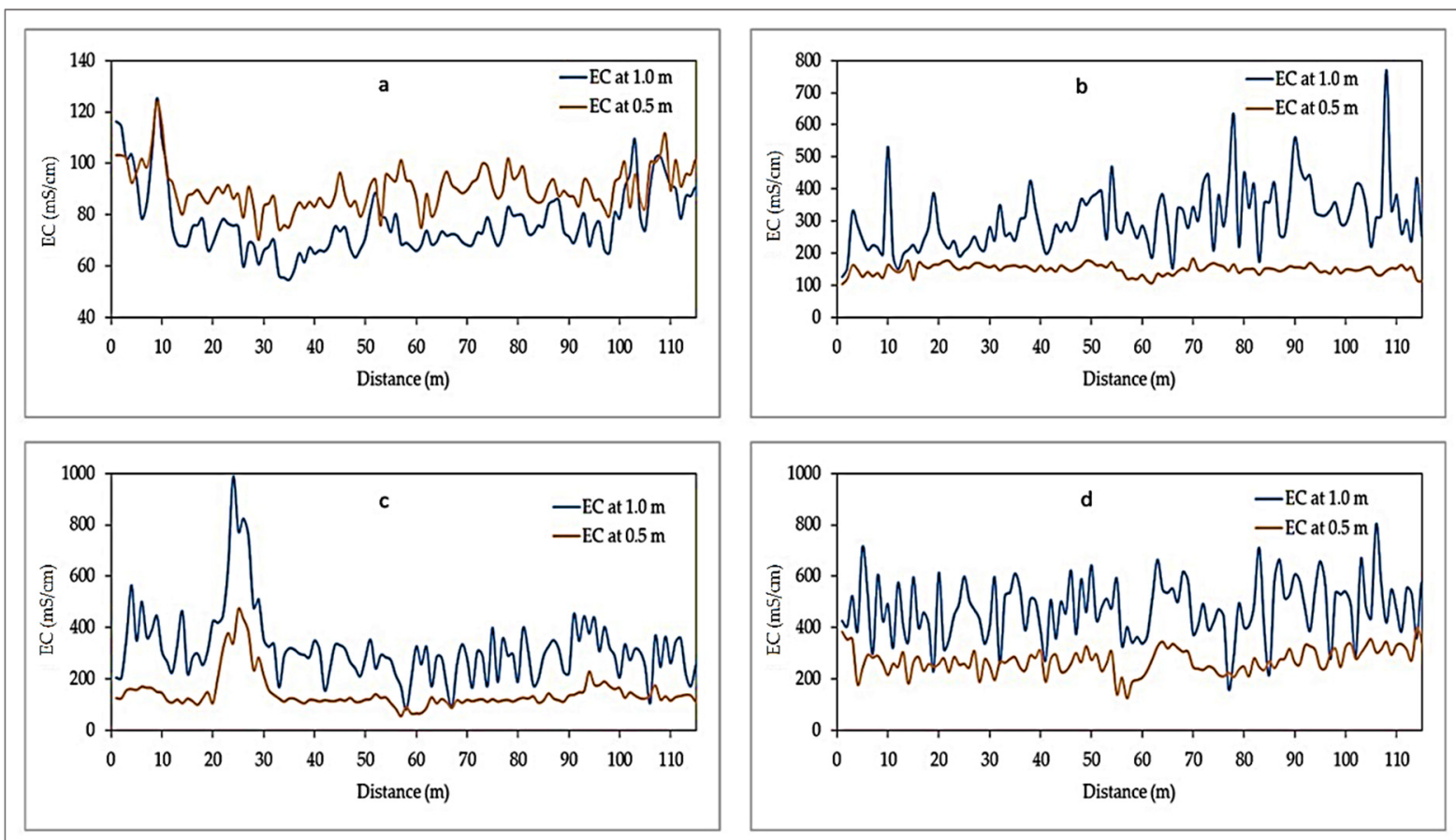

Figure 12. Electrical conductivities along Em38 at four tested locations (P-4, P-7, P-8, and P-10). Lines 4 at P-4 (a), Line 7 at P-7 (b), Line 8 at P-8 (c), and line 10 at P-10 (d) across the Al-Ahsa Oasis; for location see Figure 11. 
These results are an excellent match with what was reported by El Najem [21]. El Najem [21] reported that soil chemical properties exhibited slightly alkaline $\mathrm{pH}$ values between 7.33 and 7.86, while, the soil salinity data, as EC values, varied across the Al-Ahsa Oasis. He found several values that exceeded $400 \mathrm{mS} / \mathrm{m}$ (i.e., the minimum value of saline soils), reaching $7.80 \mathrm{dS} / \mathrm{m}$, implying the persistence of soil salinity conditions (i.e., saline soil) in the Oasis's agricultural soils. Moreover, the author reported that the soil EC values increased with increasing soil depths, signifying the inefficient drainage systems and salinization of the soil profile in the Oasis.

\section{Conclusions}

Implementing electrical resistivity tomography (ERT) and modern electromagnetic induction techniques contributed to soil characterization salinity and mapping hardpan layer problems at Al-Ahsa Oasis, Eastern Province, Saudi Arabia. The tomograms of ten acquired 2-D resistivity profiles and data of the excavated soil pits judged by local farmers indicated the different geoelectrical layers. Information about the depth thickness of these geoelectric layers, including the topmost soil, was given. In some of the 2-D tomograms and at shallow depths, the hardpan layer was depicted, and this layer was composed of marl, clay, mudstone, or shale. This layer directly affects the level of soil water. Thus, the accumulation of salt in some locations results in some of the sites affected by the salt composed sabkha, especially if it is very shallow, which increases the soil conductivity. The 2-D tomographs measured at the southwest displayed resistivity values different to those those measured at the north and east of the study area, which were characterized by low resistivity values at greater depths due to effect of the sabkha and clayey soil and effects of both the Al Yuoun evaporation lake at the north of the Al-Ahsa Oasis and of the $\mathrm{Al} \mathrm{Asfar} \mathrm{Lake} \mathrm{at} \mathrm{the} \mathrm{east} \mathrm{of} \mathrm{the} \mathrm{Oasis.} \mathrm{The} \mathrm{results} \mathrm{of} \mathrm{the} \mathrm{twenty} \mathrm{measured} \mathrm{electrical}$ conductivity profiles using the EM38-MK2 in the vertical mode were conducted at two different coil separations ( $1 \mathrm{~m}$ and $0.5 \mathrm{~m}$ ) at the same locations of the measured 2-D profiles. The electrical conductivity results showed that the salinity variation along the measured profiles changed laterally and vertically due to changes in soil type/texture, soil moisture, and the existence of sabkha. The measured conductivity at most lines indicated high values of conductivities at coil separation of $1 \mathrm{~m}$ (greater depth); these profiles were located at the north and east of the study area, while only a few lines showed high values of conductivities measured at a coil separation of $0.5 \mathrm{~m}$ (shallow depth) compared to those at $1 \mathrm{~m}$ coil separation, these lines were located at the southwest of the study area. Moreover, it is found that the farms located in the southwest of the study area were characterized by low conductivities, while relatively high conductivities characterized the farms located to the north and east in the Al-Ahsa oasis. Thus, modern geophysical techniques proved to be efficient and effective tools for the nonintrusive gathering of continuous agricultural field data on many soil types, soil conditions, soil salinity, and near-surface conditions. Monitoring data about both soil and irrigation water was very important to prevent the degrading of agricultural soils in Al-Ahsa oasis. Degrading of agricultural soils will lead to poor agricultural productivity. The productivity limiting factors of these soils were mainly integrated into their chemical properties represented by the increased salinity. Such contribution provides technical support for planners, decision makers, and researchers in the field of agricultural sciences for ensuring agriculture sustainability in this Oasis.

Author Contributions: Conceptualization, A.E.M., M.M. and Y.A.; methodology, A.E.M.; software, A.E.M.; validation, M.M., A.E.M. and Y.A.; formal analysis, A.E.M.; investigation, A.E.M.; resources, M.M., A.E.M. and Y.A.; data curation, A.E.M.; writing-original draft preparation, M.M., A.E.M. and Y.A.; writing-review and editing, M.M., A.E.M. and Y.A.; visualization, M.M. and A.E.M. All authors have read and agreed to the published version of the manuscript.

Funding: The authors appreciate the Deanship of Scientific Research, King Faisal University, and extend their appreciation to the Deputyship for Research \& Innovation, Ministry of Education in Saudi Arabia, for funding this study through project grant no. 150220. 
Institutional Review Board Statement: Not applicable.

Informed Consent Statement: Not applicable.

Data Availability Statement: Not applicable.

Acknowledgments: The authors would like to express their sincere appreciation to the Deanship of Scientific Research, King Faisal University, for financial support of this study. Special thanks go to Mohamed Al Kulaib and Mohamed Al Firij for their assistance in the geophysical data acquisition.

Conflicts of Interest: The authors declare no conflict of interest.

\section{References}

1. Ellwood, B.B.; Harrold, F.B.; Marks, A.E. Site Identification and Correlation Using Geoarchaeological Methods at the Cabeço do Porto Marinho (CPM) Locality, Rio Maior, Portugal. J. Archaeol. Sci. 1994, 21, 779-784. [CrossRef]

2. Powers, C.J. Surface-Geophysical Investigation of the University of Connecticut Landfill, Storrs, Connecticut; US Department of the Interior, US Geological Survey: Reston, VA, USA, 1999; Volume 99.

3. Attwa, M.; El Mahmoudi, A.; Elshennawey, A.; Günther, T.; Altahrany, A.; Mohamed, L. Soil Characterization Using Joint Interpretation of Remote Sensing, Resistivity and Induced Polarization Data along the Coast of the Nile Delta. Nat. Resour. Res. 2021, 30, 3407-3428. [CrossRef]

4. Griffiths, D.H.; Barker, R.D. Two-dimensional resistivity imaging and modelling in areas of complex geology. J. Appl. Geophys. 1993, 29, 211-226. [CrossRef]

5. Allred, B.J.; Freeland, R.S.; Farahani, H.J.; Collins, M.E. Agricultural Geophysics: Past, Present, and Future. In Proceedings of the 23rd Symposium on the Application of Geophysics to Engineering and Environmental Problems, Keystone, CO, USA, 11-15 April 2010; pp. 190-202.

6. Allred, B.J.; Daniels, J.J.; Ehsani, M.R. Handbook of Agricultural Geophysics; CRC Press: Boca Raton, FL, USA, 2008; ISBN 9781420019353.

7. Friedl, M.A. 6.06-Remote Sensing of Croplands. In Comprehensive Remote Sensing; Liang, S., Ed.; Elsevier: Oxford, UK, 2018; pp. 78-95, ISBN 978-0-12-803221-3.

8. Mohammed, M.; Riad, K.; Alqahtani, N. Efficient iot-based control for a smart subsurface irrigation system to enhance irrigation management of date palm. Sensors 2021, 21, 3942. [CrossRef] [PubMed]

9. Mohammed, M.; Sallam, A.; Munir, M.; Ali-Dinar, H. Effects of deficit irrigation scheduling on water use, gas exchange, yield, and fruit quality of date palm. Agronomy 2021, 11, 2256. [CrossRef]

10. Williams, B.G.; Hoey, D. The use of electromagnetic induction to detect the spatial variability of the salt and clay contents of soils. Aust. J. Soil Res. 1987, 25, 21-27. [CrossRef]

11. Triantafilis, J.; Huckel, A.I.; Odeh, I.O.A. Comparison of statistical prediction methods for estimating field-scale clay content using different combinations of ancillary variables. Soil Sci. 2001, 166, 415-427. [CrossRef]

12. Tromp-van Meerveld, H.J.; McDonnell, J.J. Assessment of multi-frequency electromagnetic induction for determining soil moisture patterns at the hillslope scale. J. Hydrol. 2009, 368, 56-67. [CrossRef]

13. Hanson, B.R.; Kaita, K. Response of Electromagnetic Conductivity Meter to Soil Salinity and Soil-Water Content. J. Irrig. Drain. Eng. 1997, 123, 141-143. [CrossRef]

14. Lesch, S.M.; Corwin, D.L.; Robinson, D.A. Apparent soil electrical conductivity mapping as an agricultural management tool in arid zone soils. Comput. Electron. Agric. 2005, 46, 351-378. [CrossRef]

15. Yao, R.; Yang, J. Quantitative evaluation of soil salinity and its spatial distribution using electromagnetic induction method. Agric. Water Manag. 2010, 97, 1961-1970. [CrossRef]

16. El Mahmoudi, A.S.; Hussein, A.A.; Al-Molhem, Y.A. Mapping of soil salinity using electromagnetic Inductive Method at the Agricultural Research Station of KFU, AI Hassa, KSA. Ecol. Environ. Conserv. 2015, 21, 85-95.

17. Doolittle, J.A.; Sudduth, K.A.; Kitchen, N.R.; Indorante, S.J. Estimating depths to claypans using electromagnetic induction methods. J. Soil Water Conserv. 1994, 49, 572-575.

18. Jaynes, D.B.; Novak, J.M.; Moorman, T.B.; Cambardella, C.A. Estimating Herbicide Partition Coefficients from Electromagnetic Induction Measurements. J. Environ. Qual. 1995, 24, 36-41. [CrossRef]

19. Al Tokhais, A.S.; Rausch, R. The Hydrogeology of Al Hassa Springs. In Proceedings of the 3rd International Conference on Water Resources and Arid Environments, Riyadh, Saudi Arabia, 16-19 November 2008; Volume 1, pp. 16-19.

20. Almadini, A.M.; El-Garawany, M.M.; Al-Omran, A.A. Evaluation of Soil Salinity and Soil Fertility at Al-Hassa Oasis, KSA; Final Report of Research Project no. at-25-30; King Abdulaziz City for Science and Technology (KACST): Riyadh, Saudi Arabia, 2012.

21. El Najem, F.A.M. Evaluating the Degraded Agricultural Soils at Al-Hassa Oasis, KSA; King Fasisal University: Al Hofuf, Saudi Arabia, 2021.

22. El Mahmoudi, A.; Hussein, A.H.A.; Al-Molhem, Y. Modern Techniquesfor Mapping Soil Salinity and the Hard Pan Layer at the Agricultural and Research Station of KFU, Al Hassa, KSA. Int. J. Water Resour. Arid Environ. 2016, 5, 63-71.

23. Abderrhman, W.A.; Bader, T.A. Remote Sensing use in the management of Agricultural Drainage Water in Al Hassa Oasis of Saudi Arabia. Remote Sens. Eval. Manag. Irrig. 1992, 42, 237-246. [CrossRef] 
24. Al-Barrak, S.A. Characteristics of some soils under date palm in Al-Hassa Eastern oasis, Saudi Arabia. J. King Saud Univ. Agric. Sci 1992, 2, 115-130.

25. Al-Barrak, S.A. Soil Characteristic of Al-Hassa Oasis; Fial Report; Water Studies Center, King Faisal University: Al-Hassa, Saudi Arabia, 1993.

26. El Prince, A.M. National Fertilizer Program for Date Palm: Al-Hassa Phase; Final Report; Water Studies Center, King Faisal University: Al-Hassa, Saudi Arabia, 2003.

27. Al-Dakheel, Y.Y.; Hussein, A.H.A.; El-Mahmoudi, A.S.; Massoud, M.A. Soil, water chemistry and sedimentological studies of Al Asfar evaporation lake and its inland sabkha, Al Hassa Area, Saudi Arabia. Asian J. Earth Sci. 2009, 3, 142-162. [CrossRef]

28. Al-Barrak, S.; Al-Badawi, M. Properties of some salt affected soils in Al-Ahsa, Saudi Arabia. Arid Soil Res. Rehabil. 1988, 2, 85-95. [CrossRef]

29. Almadini, A.M.; Al-Safarjalani, A.M.; Al-Naeem, A.A. Spatial variations in chemical properties of irrigation groundwater at Al-Hassa Oasis, Kingdom of Saudi Arabia. Arab Gulf J. Sci. Res. 2007, 25, 207-218.

30. Al Safarjalani, A.M.; Al-Dakheel, Y.Y.; El-Mahmoudi, A.S. Radionuclide levels in soil of Al Hassa. J. Environ. Sci. 2007, 34, 151-174.

31. Hussein, A.A.; El Mahmoudi, A.S.; Al Molhem, Y.A. Assessment of the validity of different types of irrigation water for agricultural purposes at Al Hassa Oasis, KSA (Kingdom of Saudi Arabia). Ecol. Environ. Conserv. 2016, 22, $1621-1627$.

32. El-mahmoudi, A.S.; Hussein, A.A.; Hofouf, A. Hydrochemical Studies of Groundwater at Al Hassa Oasis, Eastern Region, Saudi Arabia. Adsorption 2017, 6, 20-32.

33. McDowell, P.W.; Barker, R.D.; Butcher, A.P.; Culshaw, M.G.; Jackson, P.D.; McCann, D.M.; Skipp, B.O.; Matthews, S.L.; Arthur, J.C.R. Geophysics in Engineering Investigations; CIRIA: London, UK, 2002; Volume 19.

34. Mussett, A.E.; Khan, M.A.; Button, S. Looking into the Earth: An Introduction to Geological Geophysics; Cambridge University Press: Cambridge, UK, 2000; Volume 83, ISBN 9780511810305.

35. Reynolds, J.M. An Introduction to Applied and Environmental Geophysics; John Wiley \& Sons: Hoboken, NJ, USA, 2011; ISBN 0471968021.

36. McNeill, J.D. Electromagnetic Terrain Conductivity Measurement at Low Induction Numbers; Technical note TN-6; Geonics Limited: Mississauga, ON, Canada, 1980; Volume 6, p. 13.

37. Sasaki, Y. Resolution of resistivity tomography inferred from numerical SIMULATION1. Geophys. Prospect. 1992, 40, 453-463. [CrossRef]

38. Loke, M.H.; Barker, R.D. Rapid least-squares inversion of apparent resistivity pseudosections by a quasi-Newton method. Geophys. Prospect. 1996, 44, 131-152. [CrossRef]

39. El Mahmoudi, A.S.; Hussein, A.H.; Al-Dakheel, Y.Y.; Massoud, M.A. Evaluating the Degraded Agricultural Soils at Al-Hassa Oasis, KSA. Int. J. Water Resour. Arid Environ. 2014, 3, 84-95.

40. Hotzl, H.; Maurin, V. Geologic history of the Al Hasa area since Pliocene. In Quaternary Period in Saudi Arabia; Al-Sayari, S.S., Zotl, J.G., Eds.; Springer: Vienna, Austria, 1978. 